\title{
Appropriation, Additive Approaches and Accidents: The Sampler as Compositional Tool and Recording Dislocation
}

\author{
Paul Harkins \\ Edinburgh Napier University \\ University of Edinburgh \\ p.harkins@napier.ac.uk \\ p.m.harkins@sms.ed.ac.uk
}

\begin{abstract}
Brian Eno describes the recording studio as a compositional tool that has enabled composers to enjoy a more direct relationship with sound. This article will explore the use of the digital sampler as one of the studio tools that forms part of this creative process and focuses on interviews with a group of Edinburgh musicians called Found who successfully combine the writing of pop songs with the sampling of found sounds. The core song-writing partnership share an art school background and I was keen to discover if they use the sampler and other tools to sculpt sound in a similar way to how they draw or paint. Much of the academic literature on digital sampling within popular music studies has been skewed towards its disruptive consequences for copyright law and, while legal and moral questions are still relevant, I am keen to concentrate on the processes of music making and the aesthetic choices made by composers and producers in the studio. Recent ethnographic work by Joseph Schloss has centred on these questions in relation to hip-hop and it is important to examine and understand how the sampler continues to be used by musicians and producers in a variety of genres.
\end{abstract}

Keywords: art; digital sampling; hip-hop; pop; recording studio; technology.

\section{Introduction}

The digital sampler was originally conceived in connection with what Ragnhild Brovig-Hanssen calls, "transparent mediation", (Brovig-Hanssen: 2010) where samples are "discrete or hidden" in an attempt to imitate musical instruments or disguise mistakes. Tricia Rose reminds readers of her work how hip-hop reconfigured this use of the sampler and writes that, "rap producers have inverted this logic, using samples as a point of reference, as a means by which the process of repetition and recontextualisation can be highlighted and privileged". (Rose: 1994, p. 73) Joseph Schloss quotes from an issue of Electronic Musician magazine to show that when new digital samplers were becoming more affordable in the mid-1980s, it was assumed that they were "the digital equivalent of musique concrete" (Schloss: 2004, p. 34) and would take over many of the cutting and splicing techniques associated with magnetic tape recording. Few, however, could have predicted that hip-hop producers would use samplers to reproduce the rhythms of their favourite funk recordings, but this "looping 
aesthetic" (p. 33) and particular approach to music production may now be less significant as it experiences creative exhaustion and allows a range of different approaches to flourish. The way in which sampling became synonymous with hip-hop and quotation at the expense of other definitions of the term has led to a number of problems that I would like to outline and address in this article.

Firstly, academics have developed an interest in legal issues, based on a vulgar Marxism and economic determinism, which may overemphasise the role of the law in making musical decisions. In a still very useful article on digital sampling, rap music and the law in cultural production, Thomas G. Schumacher (1995, p. 254) writes that "current intellectual property rights articulate the limits of the cultural raw materials available for musical production as well as defining the formal boundaries of acceptable end-products". However, copyright does not necessarily impose limits on creative choices in the recording studio but can prevent illegal forms of cultural production from being distributed to a mass audience. Frith and Marshall (2004, p. 13) make it clear that it is misleading to conclude that "what the industry does (music publishing, record making, rights management and so on) is determined by what the law allows it to do" although the contributors to their collection still focus predominantly on "the way in which the present copyright system restricts rather than encourages creativity; limits rather than supports musical activity". (p. 16) Rather than dwelling on copyright as a possible form of censorship, it might be more helpful to acknowledge the way it is now more likely to be ignored by large swathes of musicians and consumers who see it as irritating and irrelevant, and the reluctance of rights owners to take action against musicians which might be counter-productive or damaging to the company's reputation. Well-documented legal cases brought against artists in the UK, like The KLF (Frith: 1993, pp. 4-6; Greenfield and Osborn: 2004) and Shut Up and Dance in the 1980s and 1990s, appear to be less common and copyright infringement is just as likely to lead to an increase in career opportunities and the public profile of producers as it is bankruptcy, as Danger Mouse discovered after producing The Grey Album. ${ }^{1}$ Copyright is also less likely to place restrictions on the creativity of artists whose work tends to circulate in economies that operate under the radar of major labels and publishers. It is a group of semi-professional artists operating primarily at local level who will be the focus of this case study and who have avoided legal action from rights owners over possible infringements because their work has largely gone unnoticed.

The second consequence is that the academic approach to digital sampling as appropriation and quotation has often been based on ideas derived from the study of language and literature such as African-American traditions of signifying and French theories of intertextuality. (See Danielsen: 2006, pp. 56-60 for a discussion of signifying and intertextuality in relation to funk and Bartlett: 1994 for connections between an African-American diasporic aesthetic and sampling in hip-hop.) In their classic study of the relationship between art schools and British pop, Simon Frith and Howard Horne argue that categories derived from literary criticism may not always be helpful in understanding popular culture. This is because literary criticism places emphasis on the text, "when what we have to understand are the processes within which something becomes a text: production and consumption". (Frith \& Horne: 1987, p. 5) Applying theories from literature might not be so useful from the point of view of reception as listening (and dancing) to music clearly involves different biological processes to reading, but it might be fruitful to examine similarities between different forms of creative practice as I will do in this case study with visual artists who are also musicians. Serge Lacasse discusses sampling in the work of hip-hop producer Puff Daddy as part of his attempt to apply the theory of hypertexuality to music and identifies some of the problems inherent in trying to transfer concepts from one artistic medium to another. The use of quotation marks to acknowledge "the actual insertion of an excerpt from a given text within another" (Lacasse: 2000, p. 38) is not possible in music and, like plunderphonics pioneer, John Oswald, Lacasse recognises that 
"manipulations can make it difficult to identify the recording from which the quotation has been extracted". (p. 39) ${ }^{2}$ These kinds of manipulations are relevant to the musicians who will form the basis of this case study and whose approach to sampling has as much in common with the use of everyday sounds and musique concrete than quotation. Lacasse also points out that there are a series of musical practices that have no equivalents in literature such as remixing, which is "directly related to the technology of multitrack recording". (p. 49) Digital sampling also needs to be understood within the history and context of recording technology and it is, therefore, important to focus on this tool and instrument within the context of the recording studio with empirical evidence about the specific practices of musicians, something which has too often been ignored in the field of popular music studies in favour of a focus on audiences and consumers. $^{3}$

Thirdly, while some of the most useful work on sampling has been produced by scholars of hip-hop, it has also been concerned at times with cultural and tactical priorities that neglect important aesthetical issues and questions. Tara Rodgers writes that,

Tricia Rose's study of hip hop culture, Black Noise, provides the most eloquent and detailed analysis of sampling available. Rose grounds hip hop sampling practices in Afrodiasporic expressive traditions and provides extensive evidence of how digital music tools can be employed to articulate specific cultural and musical priorities. (Rodgers: 2003, p. 314)

However, Rose too often focuses on sampling as a "tactical priority" (Rose: 1994, p. 73) rather than the musical priorities and aesthetic choices made by producers in the recording studio. She also appears to be guilty of a rather crude essentialism by concentrating on "black cultural priorities" (p. 75) that might not be so helpful in distinguishing between the surreal sampladelia of De La Soul and the Malcolm Xinspired militancy of Public Enemy. ${ }^{4}$ They may have both come from the same suburbs of Long Island and their music contained similar Afrocentric messages, but De La Soul's was a black (flower) power expressed with colourful playfulness. While Public Enemy's Hank Shocklee and the Bomb Squad restricted themselves to sampling the back catalogues of black artists like James Brown, Isaac Hayes, and Kool and the Gang, De La Soul and producer Prince Paul were wandering through the dusty grooves of white rock acts like The Turtles, Hall and Oates, and Steely Dan. ${ }^{5}$ Their idea of educational material was not black history lessons but how-to-learn French tapes and musical multiplication for kids. The experimentalism of De La Soul appears to have been more influential in hip-hop's evolution than the cultural politics of Public Enemy, and Joseph Schloss reflects that "producers are not particularly concerned with using samples to make social, political or historical points. In fact, symbolic meaning is almost universally overstated by scholars as a motive for sampling". (Schloss, p. 146)

Lastly, the focus on hip-hop has been at the expense of examining other genres especially when, as Eliot Bates argues, "in contemporary computer-based audio recording, every moment of recorded sound is essentially a "sample." Thus, rock ' $n$ ' roll, country, blues, and classical genres not traditionally associated with sampling are now sample-based musics". (Bates: 2004, p. 283) While there has been some useful journalistic and academic work on the ways in which the digital sampler reshaped British pop music of the 1980s (See Beadle: 1993; Warner: 2003), there are other histories and analyses still needed to trace the development of the device across all genres of popular music; from analogue incarnations such as the Mellotron and its use by progressive rock artists to re-create the sounds of existing instruments, to more sophisticated digital devices that can create a larger repertoire of new and unimaginable sounds through sampling existing recordings or the sounds of everyday life. What has been neglected is the use of the sampler as a compositional tool and in this article I hope to take some small steps towards rectifying this by exploring the use 
of the digital sampler as one of the studio tools that forms part of the creative process. It is necessary to continue Schloss's excellent work by concentrating on the processes of music making and the aesthetic choices made by composers and producers in the studio. To do so, I will use material drawn from interviews with a group of Edinburgh musicians called Found who successfully combine the writing of pop songs with the sampling of found sounds. The case study will focus on the core song-writing partnership, who share an art school background, and use producer Brian Eno's ideas about the history of recording technology to discover if they use the sampler and other studio tools to sculpt sound in a similar way to how they draw or paint.

\title{
The Sampler as Compositional Tool
}

In 1979, at an event sponsored by The Kitchen, New York's home of avantgarde film and music, Brian Eno gave a lecture on 'The Studio as Compositional Tool'. A few years later, in 1983, it was published as an article in consecutive issues of Downbeat magazine and, more recently, it was collected in Christoph Cox and Daniel Warner's Audio Culture (2004), where it sits proudly alongside other important pieces by Glenn Gould, Chris Cutler, John Oswald, and Kodwo Eshun on music in the age of electronic (re)production. Eno's focus is the effects of recording technology in the twentieth century and the possibilities that it offers for the process of composing and making music. His central argument is that it challenges an art music paradigm based on notation where composers, conductors, and performers work in three very separate stages to reproduce the original idea(s) of the composer. Notation provides its own restrictions on the imagination before a conductor is invited to interpret these notes on a page and communicate his instructions to a group of, what Eno (2004, p. 129) refers to as, "intransigent musicians". This is based on his experience of collaborating with classical performers, which one can only assume has been particularly painful. This tripartite process involves what he calls "transmission loss" (ibid.) at every stage as meanings are lost and misinterpreted, and there is a fourth problem connected with the performance of the piece and the unpredictable nature of acoustic spaces. Recording, on the other hand, has enabled composers to enjoy a closer relationship with sound. Eno writes that:

\begin{abstract}
In a compositional sense this takes the making of music away from any traditional way that composers worked...and one becomes empirical in a way that the classical composer never was. You're working directly with sound, and there's no transmission loss between you and the sound - you handle it. It puts the composer in the identical position of the painter - he's working directly with a material, working directly onto a substance, and he always retains the options to chop and change, to paint a bit out, add a piece, etc. (ibid.)
\end{abstract}

It is worth asking whether Eno is being too simplistic about the nature of classical composition and if he is also making the mistake of comparing a collaborative activity with the more individualistic process of painting. Perhaps the art music paradigm he describes has more in common with film or theatre where the scriptwriter or playwright, director, and actors have similar roles to the composer, conductor, and performers; arguments over artistic interpretations are inevitable. Eno wants to remove musicians as far as possible from the compositional process so that his own ideas can be fully realised and this seems to rest on a very Romantic notion of the individual author as the creator of meaning. The idea of genius usually associated with Western art music finds its way into the worlds of popular music and the work of record producers who have wanted to limit opportunities for the active involvement of audiences. Eno appears to forget that listeners have gained the possibility of more control over acoustic space while listening to recordings in the comfort of their living rooms as a result of developments in stereo and the opportunities offered by graphic equalisation, but audio 
obsessives like Brian Wilson and Phil Spector were well aware of the consequences. As stereo started to become the standard format for recorded music, Spector wanted to go "Back to Mono" (Zak: 2001, p. 148) and Wilson, too, was opposed to a development which allowed the listener too much control over his sonic masterpieces:

I look at sound like a painting, you have a balance and the balance is conceived in your mind. You finish the sound, dub it down, and you've stamped out a picture of your balance with the mono dubdown. But in stereo, you leave that dubdown to the listener - to his [or her] speaker placement and speaker balance. It just doesn't seem complete to me. (ibid.)

These references to painting with sound and handling it as part of a more direct relationship might also be an accurate description of the way in which the digital sampler is one of the studio tools or instruments that form part of a more tactile approach to composition.

Albin Zak writes in The Poetics of Rock that "the practice of combining multiple sonic images into a single composite [has] always [been] part of the recording process". (Zak, p. 16) I aim to explore how the digital sampler might have extended this further by examining the way in which Found's musical priorities have moved away from appropriation of existing recordings towards a recontextualisation of found sounds that is influenced as much by their study of art as their love of hip-hop. Keen to discover if the core song-writing partnership of Campbell/Perman used the sampler and other tools and instruments to sculpt sound in a similar way to how they paint or express their ideas in visual art, I constructed the following research questions, which, in retrospect, proved to be quite naïve in relation to their practice: What does the artist's studio look like (if indeed it is a single place) and how important is the sampler in the song-writing process and studio work? What do they prepare beforehand in terms of melody, lyrics and song structure or is the whole piece constructed in the studio? Does the sampler form part of what Eno describes as "an additive approach to recording" which enables musicians "to chop and change, to paint a bit out, add a piece"? Before going on to examine some of the answers to these questions, I will begin by providing some useful contextual information about the band and discussing the influences which have shaped their approach to the art of sampling.

\section{Finding Influences, Defining Sampling}

Found began making music in 2001 or 2002 depending on whether you read the biography on the band's website or their own record label's website. They describe themselves as "five scruffy lads from Edinburgh who make music which 'blends bubbling dancefloor introspection with textured folk pop."' (Surface Pressure Records: 2006) A journalist from the News of the World, a tabloid newspaper better known for its coverage of undercover celebrity stings and salacious sex scandals than exclusives on experimental pop music, also referred to their appearance when he wrote: "They look like vagrants - but when it comes to ideas, they're one of the richest bands around. Found sound like a punch-up between Paolo Nutini and Captain Beefheart". (Barr: 2008) Formed by friends, Tommy Perman, Ziggy Campbell, and Kevin Sim, while studying at Gray's School of Art in Aberdeen, the band have been involved in a variety of visual and musical art projects and, much like the fabled history and discography of Manchester's Factory Records, their catalogue numbers extend to launch parties, documentary films, exhibitions, and performances, including one called 'Flight Path' which involved members of the audience throwing paper airplanes through a laser beam to trigger sounds. Their merger of playful art school experimentalism with a pop aesthetic can be heard on their first two full-length albums, Found Can Move, released in 2006 on their own label, Surface Pressure Records, and This Mess We Keep 
Reshaping, which was released in 2007 by Fife's Fence Records, a folk collective which includes artists like King Creosote and James Yorkston.

As individuals in a small group, Tommy and Ziggy have approached the sampler from quite different perspectives, and this becomes apparent in their answers about which musicians and producers they particularly admire for their creative use of the sampler. For Tommy, a love of hip-hop provided the introduction to sample-based music and he talks of early attempts to use cassette decks and four track recorders to "re-create that sampling aesthetic of looping stuff up". (Perman: 2008) He then moved on to Cubase before joining forces and financial resources with his younger brother, the producer S-Type, to purchase an Akai MPC 2000. Along with an increase in the sophistication of technological tools at his disposal, the creative use of the digital sampler by a number of significant hip-hop producers was leading to changes in his listening pleasures and artistic inspirations. Tommy explains that,

in terms of sampling it would be people like Geoff Barrow and the Portishead sound which I discovered at the same time as a lot of hip-hop. DJ Premier and everything that he did I loved. DJ Shadow is another obvious one to say but what he was doing on Entroducing and the records leading up to that were hugely influential on me in terms of listening to music and it opened my ears up to a lot of pretty weird prog rock and stuff. Then latterly people like Matthew Herbert who I find very interesting musically because he writes very highly structured melodic songs but always has a very detailed approach to his production method and he's got his own manifesto. It's very conceptual and obviously very learned. And then Prefuse 73 was a huge influence with his One Word Extinguisher album which I listened to to death. [It] is so melodic and built entirely on an MPC. That was a real eye opener as to what that technology could do. (ibid.)

While hip-hop remains a key ingredient in his approach to sampling, Tommy's tastes have widened from legendary New York based producers such as DJ Premier and Pete Rock, who zealously maintain the secretive tradition of "digging in the crates" (Schloss: 2004) of second-hand record stores for rare break-beats, to artists like Geoff Barrow and DJ Shadow, who have emerged from the sub-genre of trip-hop with similar methodologies to hip-hop but slightly different aesthetic priorities. (See Johnson: 1996; Wilder: 2005) He is also inspired by other auteurs of the sampler like Matthew Herbert who aligns a new kind of musique concrete with microhouse on his Around the House album and musique concrete with big band jazz on the Goodbye Swingtime album but is frustrated with approaches based on appropriation:

With a sampler there's no distinction between sound and music, or noise and music, and I think that's a liberation that musicians have struggled to find for years. We finally have it and instead people are using it to rip off their record collections, which confuses the hell out of me. (quoted in O'Neil: 2006)

Some of the possibilities which Herbert praises are similar to the priorities of musique concrete pioneer, Pierre Schaeffer, which I will go on to discuss, but he may underestimate the listening skills involved in identifying a small segment of music with the potential to be looped and manipulated to form part of a new recording. With producers like Premier and Pete Rock, Tommy believes,

their ear is like a good photographer, for finding that loop which is five minutes into a rare jazz tune and suddenly there's a lick that was in an improvised solo, never repeated and for whatever reason they've [sampled it]. (ibid.)

This mirrors nicely what Eno says about recording having its first significant effect on jazz and its previously "transient and ephemeral" (Eno, p. 127) improvisations becoming "more interesting as you listen to them more times. What seemed like an almost arbitrary collision of events comes to seem very meaningful on relistening". (Eno, pp. 127-8) This is especially true when these improvisations have been sampled, 
looped, and manipulated to form one of the key elements of a new recording. The saxophone solo on 'Today' by Tom Scott with The California Dreamers, released by the Impulse label in 1968, was re-used on Pete Rock and C.L. Smooth's 'They Reminisce Over You (T.R.O.Y.)' in 1992 and the repetition of the original improvisation transforms a small piece of pastoral psychedelia into a powerful requiem for the souls of lost brothers and absent father figures. One journalist has praised Pete Rock as

arguably the most sophisticated [underground beat maker of his generation], playing with carefully constructed arrangements that show sampling's true musical potential: what happens when someone simply takes the time to play with the various pieces. That's why songs on this album like "They Reminisce Over You"...have become all-time hip-hop classics - they reflect not only Pete's unmatched ears for outstanding samples, but also his ability to craft them into something greater than the sum of their parts. Pete's particular gift has been in layering, his ability to juggle in any number of different elements - a bassline twiddle here, a keyboard tinkle there, not to mention horns. (Wang: 2003, p. 34)

The sophisticated use of the sampler is similar to the producer or bandleader who is balancing and blending a number of disparate sounds to create a coherent collage and its dismissal as a lazy form of plagiarism ignores the complexities of an approach to sampling that began to frustrate Tommy. He describes falling "out of love with the idea of stealing other people's stuff, partly because it's so difficult. You have to really work a sample to...turn it in to your idea". (Perman: 2008)

Ironically, Ziggy has been moving in the opposite direction from thinking about sampling his own guitar playing towards sampling existing recordings and has been buying old records deliberately for this purpose. His other interest is in the high art proponents of tape-based sampling and he mentions being exposed to artists like John Cage and Steve Reich while studying at art college: "I like the concepts and I like reading about these guys. Sometimes more than I like the music. Steve Reich's the exception. His stuff's amazing". (Campbell: 2008) Ziggy's interest in particular post-war figures is common among popular musicians and fans who have read about the importance of Pierre Schaeffer, Pierre Henry, John Cage, and Steve Reich in the development of electronic music, but his lack of pleasure in listening to much of their recorded output is suggestive and indicates that the connections which are often made between the avant-garde and genres of popular music like hip-hop and electronic dance music may be rather tenuous in terms of musical similarities as well as the demographics of their audiences. This does not prevent journalistic hyperbole or the expression of exaggerations, even from respected critics and writers like Rob Young of The Wire magazine:

At the end of the nineties, the innovations that began with GRM [Schaeffer and Henry's Group de Recherché de Musique Concrete]'s founders have been fully integrated into the everyday working practice of almost all musicians working across the entire musical spectrum. The breakbeat, created entirely from the manipulation of records on turntables or from recorded segments spliced together manually or digitally, is the epitome of musique concrete. (Young: 2000, p. 15)

The tape splicing techniques of GRM may have evolved into or been superseded by a computer-based composition which is exploited by musicians working in a variety of genres, but where the musique concrete of Schaeffer and others is often based on the random noises of everyday life, breakbeats are usually based on the syncopated rhythms of funky drummers. (See Butler: 2006, pp. 76-88) Henry may have achieved a place in popular culture with his acid rock piece, 'Psyche Rock', which entered the French singles chart in 1967, but his early work with Schaeffer appears to have been part of a wider modernist project to destroy distinctions between music and noise which is why Henry is very quick to distance himself from the work of contemporary producers of electronic music: "People do things with computers and samples but it's not the 
same approach as the way I work, or how Karlheinz Stockhausen worked in his electronic pieces. There is not the same craft, and it's not progress". (quoted in Clark: 2009) Regardless of whether the modern myth of progress in music (Frith: 2007a) or other human activities (Gray: 2004) is possible or desirable, the processes of musique concrete and digital sampling may appear to contain some similarities. However, while artists like Found and Matthew Herbert are interested in incorporating the sounds and noises of everyday life into their music, unlike the radical avant-garde they still want to retain the rhythms, melodies, and harmonies of popular music. ${ }^{6}$ What Tommy and Ziggy have discovered is that sampling is not simply the appropriation of other people's music or ideas and they are now more interested in a hip-hop aesthetic being usefully applied to any sound source, not just recordings.

In the article 'Digital Sampling and Analogue Aesthetics', (Kvifte: 2007) Tellef Kvifte distinguishes between four meanings of sampling that are often used interchangeably even though only one is unequivocally digital. This is the first which relates to the conversion of sound from analogue to digital; the second is when an instrument is used to imitate the sound of another instrument, like the Mellotron (Samagaio: 2002) or the first Fairlight samplers (Warner: 2003), for example; the third is that of integrating existing recordings into a new recording as a sonic quotation, and the fourth type of sampling involves the use of tape splicing or digital editing to enhance studio recordings or erase mistakes. One of my favourite examples of the latter is to be found in the writings of Bill Drummond when retelling the story of their collaboration with Tammy Wynette on The KLF's 'Justified and Ancient' in 1991. Drummond flew to Nashville to record the vocals of the "First Lady of Country" (Drummond: 2001, p.183) on a backing track created in a South London studio by he and partner Jimmy Cauty, but the session was a disaster because she was used to working with a band who would slow down or speed up depending on her timing and so was only able to keep in time with the track for a few bars. On his return to the UK, Drummond feared the recording of Wynette's vocals would be unusable until Cauty explained that "we just got this new machine. We can sample up every word she sang separately - stretch them, squeeze them, get them all in time. As for her pitching, the listener will hear them as emotional integrity". (p. 185) Sampling saved the day through its digital editing capabilities and the combination of perfect timing and imperfect pitch. The irony is that the KLF expected the vocal performance to be interpreted as more authentic and to avoid accusations of artifice that have been aimed at forms of technological mediation and manipulation throughout the history of popular music from the microphone to the vocoder and Auto-Tune.

Found are more likely to use the sampler to retain and experiment with 'mistakes' rather than erase them, as I will go on to discuss, and it seems that their work, and that of producers who operate in a similar way, does not fit neatly into any of Kvifte's four categories. It adheres to processes related to the first, second, and third definitions of sampling, although not without a slight reconfiguration. Their approach develops out of a clearly defined aesthetic of appropriation and evolves into using the sampler to create new musical instruments rather than imitate existing ones. Tommy says:

From my point of view, the definition of sampling is the process of recording a sound, having it in what would be a sampler, a bit of technology, that can play back a sound on demand. It doesn't matter where that sound source comes from. You can then use that to manipulate. We always manipulate the sample no matter if it's come off a record or if it's a guitar strum. That, or the sort of ring after you play the guitar chord, becomes a really interesting keyboard sound once put into a sampler and played over the octaves. I think that's definitely sampling. Or you would take your voice and then pitch it and manipulate it. That's sampling. (Perman: 2008)

For reasons of financial necessity, Found will use software like Logic in ways associated with Kvifte's second category of sampling and are not averse to re-creating

I@J vol.1, no.2 (2010) http://www.iaspmjournal.net 
one of the uses of the Fairlight or other early digital samplers by choosing to imitate the sound of a Fender Rhodes Mark II from a massive library of different keyboard instruments. They do not rule anything out of their approach to sampling and, unlike Matthew Herbert, they do not have a manifesto. Inspired by the vow of cinematic chastity taken by the Danish filmmaker Lars Von Trier and his Dogme collective in 1995, Herbert has drawn up a Personal Contract for the Composition of Music (P.C.C.O.M.). One of these self-imposed commandments states that "no replication of traditional acoustic instruments is allowed where the financial and physical possibility of using the real ones exists". (Herbert: 2005) If asked to follow this particular type of pop puritanism, Found could probably plead poverty, but they would fall foul of Herbert's rule relating to Kvifte's third definition that "the sampling of other people's music is strictly forbidden". (ibid.) For Found, if a recording by another group or artist contains a combination of sounds that are "dying to be sampled," (Perman: 2008) they will do so, often out of creative curiosity.

\section{Sampling Found Sounds: Appropriation, Additive Approach, and Accidents}

An example of Found's approach to appropriation can be heard on a track from This Mess We Keep Reshaping called 'Some Fracas of a Sissy'. It is one of the few Found songs with an obvious sample from an existing recording, even though its identity is not instantly recognisable. Called 'Night Life in Shanghai (Ye Shanghai)' by the Chinese singer Zhou Xuan ${ }^{7}$, a short burst of trumpet from it is used between the first two verses. Ziggy explains:

It's a straight lift. I sorta liked it because it wasn't like we were just taking a groove from it and building a whole tune. I knew we'd taken horns and a little bit of the female vocal and then when I built the track I thought, fuck it. I'm just going to let people hear where l've taken this from. (Campbell: 2008)

After the second verse the small trumpet sample is followed by the vocals of Xuan from a larger segment of the original recording and this act of revelation is, according to Tommy, a common tactic among some hip-hop producers who will use a small sample throughout a new recording before finally disclosing their source by extending its length. This enables the listener to make the connection between the new and the existing recording and the producer receives instant recognition for cleverly disguising and manipulating a sample from a source which was previously unclear.

A more typical example of Found's use of the sampler as a compositional tool can be found on a track from their first album, Found Can Move, called 'Static 68', for which the starting point was not melody, lyrics, song structure, or musical ideas taken from an existing recording. It is a more experimental approach that focuses on more unusual sounds and those that might normally be considered insignificant but does not claim to be revolutionary or avant-garde:

I don't want this too sound too pretentious but it starts with an atmosphere or a character rather than chord structures. There'll be a sample that has got a bit of dirt to it that's really interesting. 'Static 68 ' started out as a record static loop which I then built lots of stuff on top of but it was actually that little static from the run out groove which was the most interesting thing for me and the whole song grew round that. (Perman: 2008)

Melodies are also derived from other strange sources such as the sound of a truck reversing before developing it into a song by adding guitar chords along with other instrumentation. ${ }^{8}$ The original sampled sound source often becomes irrelevant and, even if you listen very carefully, it is almost impossible to hear the static in 'Static 68'. The static or truck sound may even be removed at the end of the process despite being 
the "initial seed" (ibid.) for the idea. This maps directly on to Eno's description of the additive approach to recording as the digital sampler is being used "to chop and change, to paint a bit out, add a piece" and Tommy makes the comparison with "an abstract painter in the way that they keep on working a canvas until they're content and sometimes the original under painting is completely lost". (ibid.) The original musical idea is developed then discarded as new colours and shades are created and the analogy with the painter also extends to the palette of sounds that are available to musicians working with electronic tools. In 'The Studio as Compositional Tool', Eno describes how the range of their instruments limited the palettes of traditional composers:

If you carry on the painting analogy, it's like he [or she] was working with a palette, with a number of colours which were and weren't mixable. Of course, you can mix clarinets and strings to get different sounds, but you're still dealing with a range that extends from here to here. It's nothing like the range of sounds that's possible once electronics enter the picture (Eno: 2004, p. 130).

Drummer Max Roach talked of "the world of organised sound [as] a boundless palette", (quoted in Rose: 2004, p. 80) but he could easily have been referring to the world of recorded sound, which the digital sampler expands in a seemingly infinite number of ways.

The sound of malfunctioning electronics, which has become more commonly associated with the glitch genre (See Cascone: 2000; Young: 2002; Bates: 2004; Sangild: 2004), has also expanded the range of sounds in recorded music from feedback and distortion through to skipping CDs or other accidental noises. Sound artists like Yasunao Tone deliberately damage discs to create an unpleasant experience of extreme noise error, but Found are more likely to take an interest in extraneous sounds that have been captured accidentally during the recording process, which they then decide to reshape or leave intact rather than edit out. This is similar to the part of Matthew Herbert's personal contract which states that "the inclusion, development, propagation, existence, replication, acknowledgement, rights, patterns and beauty of what are commonly known as accidents, is encouraged". (Herbert: 2005) An example from Found's work is contained within the song 'See Ferg's in London' on This Mess We Keep Reshaping. Ziggy's recording of the final vocal take was interrupted by a phone call which caused him to leave the room, but, rather than edit out unwanted noises in the attempt to capture a perfect performance, we are left with the sound of a door opening to provide a short piece of punctuation and a slight pause in the proceedings "when everything's gone quiet". This is a particular approach to the recording process, but the digital sampler and laws of unintended consequences combine to create other interesting juxtapositions. A snare sound is sampled from an old recording and the crackle on a piece of vinyl combines with it to create unexpected noises once it is played over the octaves. The background sound of falling rain is mixed with a clarinet as a result of recording outdoors:

We were down at the Sculpture workshop and recorded sounds there and for me one of the nicest moments when we had this guy down who was playing the clarinet in this little pavilion with the rain beating down on it and he held some really long clean notes and as soon as he'd gone I basically fed it into the computer and started playing chords with them and it just sounded so nice. There was something so woody and organic about it with the rain crackle in the background (Perman: 2008).

Rather than aiming for the dissonance or discord of glitch, the result is a mix of musical colours that attempts to incorporate the sounds of nature rather than expel them. As well as the natural elements interfering with recordings, the noise pollution of inner city life often causes problems when working in home studios, although creatively satisfying conclusions can be found: 
Something I'm getting into just now through necessity because l've got a really noisy neighbour is just not waiting. I used to wait for quiet times to record, especially vocals because you have to have the mic quite high but now I'm just going to leave it all in. If there's someone cutting the grass l'm just going to leave it in there or a dog barking. It's the same aesthetic as the snare drum thing. It's a kind of sampling, unfettered sampling (Campbell: 2008).

Rather than battle these blights on the urban soundscape the solution for Found is to record, sample, and experiment with them as part of a new kind of musique concrete.

\title{
Going into the Studio: Domestic Spaces and Recording Dislocation
}

In his study Any Sound You Can Imagine, Paul Theberge describes the growth of home studios in the 1970 s as a private space for performers to try out musical ideas before entering professional studios to record them (Theberge: 1997) and there is still a tendency to talk about 'going into the studio' which is why I imagined melodies, lyrics, and song structures being part of a two-stage process of writing and recording. For each member of Found, though, everything occurs in the one place: "It's all done in the studio really. When we say in the studio we mean in our bedrooms but it's not like we prepare demos and then go and do it proper. It's all part of the same thing". (Campbell: 2008) Each musician defines the studio differently depending on the equipment they use. For Ziggy, the home studio itself is a misconception as it encompasses a much smaller area of private space dependent on his domestic arrangements. In The Poetics of Rock, Albin Zak writes about examples of "location recording" (Zak, p. 105) when rock bands like The Band or The Red Hot Chili Peppers have decided to leave the sometimes restrictive and pressurised environment of large state-of-the-art recording studios in favour of old mansions in Los Angeles with primitive mixing desks and outdoor swimming pools. Perhaps the way in which Found work might be described as an example of recording dislocation where each member of the band works in isolation before coming together at different points in the process when their physical presence is required. In his article 'OK Computer: Mobility, Software and the Laptop Musician', Nick Prior explains that mobile music technologies have extended

\begin{abstract}
the possibilities of collaboration and iteration. For instance, band members no longer have to be physically co-present to collaborate with each other. Software files and audio files can be easily sent through electronic or regular mail to be added to, modified or mixed, then returned for further iteration (Prior: 2008, pp. 919-920).
\end{abstract}

The mobile nature of the laptop and its ability to function as a virtual recording studio or a digital sampler means that recording music in a studio is less and less about a single location or a multiplicity of machines. The bedroom may be the location where Ziggy's contributions are composed, performed, and recorded, but Tommy explains that he and other band members can be even more flexible in terms of the spaces they use to create music: "Kev's studio is his sampler and so he'll just sit with his headphones plugged in so he can work anywhere. My studio's just built round my laptop with a few things plugged into it". (Perman: 2008) In answer to my research question about what the artist's studio looks like and similarities in artistic and musical practice, it turns out that there are no differences between the studio Tommy uses as an artist and the one he uses as a musician because they are one and the same thing:

I sit at my laptop and kill my eyes for music and art. I'll sit and draw at the very same desk where l'll write crap little melodies. I'll switch between having to do something in Photoshop to working in Ableton (Perman: 2008). 
It seems reasonable to conclude that the studio is the software and the boundaries between the role of musician and visual artist are as fluid as the flick of a cursor or the prerequisites of funding applications. When asked if Found consider themselves musicians or artists or both, Ziggy's answer is that "it depends who's paying. It depends what we're applying for". (Campbell: 2008)

The definition of musicianship has also been an issue for Brian Eno who has described himself as a non-musician or "anti-musician" (Tamm: 1995, p. 47) and in 'The Studio as Compositional Tool' he admits:

I can neither read nor write music, and I can't play any instruments really well, either. You can't imagine a situation prior to this where anyone like me could have been a composer. It couldn't have happened. How could I do it without tape and without technology? (Eno: p. 130)

Eno is one of many musicians throughout the history of popular music whose ignorance of notation has not prevented them from expressing creative ideas through the use of traditional and non-traditional instruments like the microphone, washboard, turntable, or digital sampler. The same is true of Found whose development as musicians has been defined by their use of new technological tools, but, unlike Eno who became primarily a composer and producer after leaving Roxy Music in 1973, they are very much involved in performance and their use of the sampler has interesting consequences for how the relationship between recorded music and live music is understood.

Simon Frith writes that "over the last fifty years popular music culture has been organised around the relationship of the recorded music and live music sectors and this relationship is constantly changing". (Frith: 2010, p. 2) The recent global decline in sales of recordings is leading to a greater understanding about the existence a number of music industries (Williamson \& Cloonan: 2004) with live music being the current favourite to assume economic superiority in the UK after recent estimates that it has overtaken recorded music in terms of its financial contribution to the nation's gross domestic product. (See Page: 2007; Rogers: 2009) More polemical, less evidencebased ideas can be found in Bill Drummond's suggestion that "all recorded music has run its course", (Drummond: 2008, p. 3) or Glenn Gould's prediction that "the habit of concertgoing and concert giving, both as a social institution and as chief symbol of musical mercantilism, will be as dormant in the twenty-first century as, with luck, will Tristan da Cunha's Volcano". (Gould: 1987, p. 332) This volcano on one of the world's remotest islands has been dormant since 1961, but the concert hall and the communal experience of live music continues to play a crucial role in the lives of human beings which is unlikely to disappear. In Britain, the Musicians' Union has long campaigned to "keep music live" (See Thornton: 1995, pp. 38-51) and despite fears over a decrease in employment opportunities for its members, the digital sampler does not appear to have replaced the live musician. Found's live performances provide an interesting illustration of how their experiments with the digital sampler in the studio co-exist with and complement their expression of these ideas as musicians onstage.

Found are keen to move from the dislocated recording experience, I have described above, to one where they can capture the understanding they have developed as live musicians by playing together in a larger studio. They realise this will involve a change in emphasis: from making a record composed of the multiple sonic images that Zak describes, then learning how to perform it as a live band, towards working on and rehearsing songs, then going into a studio to record them in the more traditional two-part process. This would likely involve less overdubbing which, according to Zak,

requires the performer to summon up inspired performances in the absence of not only an audience but other musicians. What in a live situation is an interactive interchange among players - a kind of musical breathing together - becomes a 
one-way responsive relationship between the musician and a fixed, unchanging musical partner, the track. (Zak p. 54)

It is the shared oxygen of music making which Found want to capture as Ziggy thinks "that something [special] happens when people play music live together". (Campbell: 2008) This does not exclude the digital sampler which is as important a part of their live performances as drums, bass, guitar, and keyboard and which limited their set list options when Kevin Sim, who programmes and plays the sampler, did not appear for a gig because he had overslept. They managed to perform five songs without him before "he appeared in the crowd and everyone cheered. It just made everything make total sense and have more impact". (Perman: 2008) The sampler had previously been used as a click track on stage for the band to keep time, but it has become an instrument of live improvisation and used with a delay pedal:

The two of them together means he can have so much variation in his sound that I think it's definitely a musical instrument. He'll trigger a sample then mess with the settings on the delay pedal and he can really change the pitch. It's a different live performance every time he uses it and that for me is an example of a really good live musician. (Perman: 2008)

Good musicianship is usually defined in this way as part of a collaborative activity whereas the digital sampler is usually thought of as a studio tool that is used by an individual. It has not been an obvious part of live performances, particularly in hip-hop where turntables, disc jockeys, and DAT machines have been used to reproduce instrumental compositions created with a sampler in the studio. It is, therefore, important to examine how the digital sampler is not just a compositional tool but is also being used as an improvisational tool on stage by Found, Matthew Herbert, and other performers who are not content to work in the isolation of their studio or for hip-hop methods of appropriation to be the dominant model of sampling creativity.

\section{Conclusion}

In his article 'Making Old Machines Speak: Images of Technology in Recent Music', Joseph Auner writes that

narratives of progress and innovation have dominated the story of music and technology throughout the twentieth century. The pursuit of ever-greater expressivity, control, responsiveness, clarity, and power, can be charted in instrument design, the whole story of hi-fidelity audio equipment, and the digital revolutions that are transforming musical production, distribution, and reception (Auner: 2000, p.1).

The digital sampler often features as part of this linear narrative towards technological utopia, which is why historical context is important in reminding us about some of the analogue possibilities that existed previously and which are now quicker and easier to execute with digital technology. Brian Eno's lack of techno-utopianism is another welcome bulwark against modernist definitions of technological progress as he highlights how advances in technology are met with constraints that are always inherent in the creative process:

everyone is constrained in one way or another, and you work within your constraints. It doesn't mean that suddenly the world is open, and we're going to do much better music, because we're not constrained in certain ways. We're going to do different music because we're not constrained in certain ways - we operate under a different set of constraints... (Eno, p. 130). 
Eno's realism is balanced by an enthusiasm for the way in which technology continues to create new musical instruments with a variety of different capacities:

There are now electronic machines that make the sounds of new musical instruments. You can just say, for example, 'I want an instrument that has sharp attack and a long decay of the sound, with the upper harmonics increasing as the decay goes on.' With a little programming you can have it. And then there are the recording studios, where you can take finite sounds and treat them as if their parameters were infinite. You can change the pitch to any extent you want, and you can change the timbre completely, change the duration, make it endlessly long or very short. Most of what pop music has been doing is experimenting with all this...The interest today isn't in developing serial music or polyphony or anything like that. It is in constantly dealing with new textures (quoted in Frith \& Horne, p. 174).

The digital sampler has incorporated many of these functions of the studio as a compositional tool and is one of the reasons why definitions of the recording studio have changed radically. In the same way that the consumption of music has moved from the concert hall to the living room to the earphone (Frith: 2001, p. 27), the recording of music has moved from booths to the bedroom to the laptop, a meta-device that enables music to be produced, distributed, and consumed. ${ }^{9}$

Eno's music has been influential and Frith and Horne argue that his ideas are important because "his accounts of pop and art are rooted in an understanding of the technological issues involved". (p. 116) Some may point to Found's amateur attitudes or semi-professional status as evidence that their practice may be of less relevance to the study of popular music than professional performers like Matthew Herbert but this would be to neglect the importance of the amateur to the field of popular music. ${ }^{10}$ One of the reasons why Found are interesting is they continue Eno's art school tradition of investing pop creativity with technological experimentalism. Their interest in new instruments, musical mobility, and messing about with mistakes is part of cultural shifts and new forms of creativity that have been enabled by digital technology. An apparent ease with the pop process and publicity of tabloid journalism is in contrast with the more puritanical approach and anti-commercial values of an artist like Matthew Herbert. They do not appear to be constrained by a lack of talent or imagination and their approach to composition does appear to confirm an extension of sonic possibilities that is being enjoyed by many producers who are working in innovative ways to create new music making methods and interesting ways of performing. Kevin Sim's use of the sampler as an improvisational tool on stage has led to him being described as an "MPC wizard" (Campbell: 2008) by a fan who stalks him in an attempt to uncover some of his secret sampling techniques and musical ingredients. Unlike computer or software-based samplers, the MPC 2000 allows a more physical relationship to develop with the instrument, something Eno sees as being vital to the music making process. ${ }^{11}$ One of the ways in which Sim uses the MPC is to sample untraceable fragments from recordings of other artists or groups to create new colours and shades. As Tommy says,

he samples off records a hell of a lot but you'd never know. He hears tones he likes and...just chop[s] a tiny little segment of it [to] create a palette of sounds, maybe just ten sounds that he can then write an entire piece with. (Perman: 2008)

The move from an appropriation-based approach based on recognisable recordings towards the manipulation of microsamples and mistakes challenges existing definitions of sampling and is another interesting development in the long history of composition and recording technology. (For more on microsampling, see Harkins: 2010) It is one that needs to be investigated further to find out if the digital sampler is another of the new musical instruments which has expanded, what George Martin calls, "the infinite palette of musical colours", (Martin: 1979, p. 76) as well as the palate of musical tastes. 


\section{Acknowledgements}

Versions of this article were presented at the Art of Record Production (ARP) conference at the University of Massachussetts, in November 2008, IASPMInternational conference at the University of Liverpool in July 2009, and a seminar at Universite Paris 1 in June 2010 where I received useful questions and comments. I would like to thank Simon Frith, Nick Prior, Martha Ulhoa, Hector Fouce, Isabelle Marc Martinez, Ivy Man, and the anonymous reviewer for feedback, suggestions, and encouragement.

\section{Notes}

1. The Grey Album (2004) consists of songs created by manipulating music from The White Album (1968) by The Beatles and overlaying rap a cappellas from Jay-Z's The Black Album (2003). It caused controversy as it began to circulate through cyberspace on illegal file-sharing networks because permission had not been sought from the owners of the songs or the recordings to execute these adaptations. The owners of The Beatles' sound recordings in the US, Capitol Records, quickly issued Danger Mouse, aka Brian Burton, with a demand to cease and desist distribution. Burton has since gone on to form one half of neosoul act Gnarls Barkley and the indie rock duo Broken Bells with the Shins' James Mercer. He has also produced albums by Beck and The Black Keys as well as the second album by Gorillaz, Demon Days (2005), which was manufactured, marketed, and distributed in the UK by EMI - the parent company of Capitol which the year before had taken legal action against Burton.

2. Oswald makes a very useful distinction between what he calls electro-quotations and his plunderphonics works: "I was really interested in that idea of legitimate quotation, which isn't built into the system", he says. "You don't have quote marks in musical notation or in recordings, for that matter. But you can annotate your sources. I tend to call the portions of things that I use Electroquotations. The thing that's perverse in the analogy with literature is that I'm very rarely just quoting. Although I tend not to filter or distort the sound, I transform it so much in time that it's not just free quotation. It's some sort of elaboration. It's like the commentary is built in. What you usually get in journalism or literature is that the quotation doesn't usually represent the whole essay. It's something that's used as a trigger point for a commentary or elaboration. In music, I think you can do those kinds of things simultaneously. You can have all sorts of things happening where the quotation is recognisable as itself, even though it's been transformed in some way. So that's when you get into this Electro-quotation thing, when the source is still familiar. It's Electro-quotation if you're making an electronic quote of something and it's Plunderphonics if you're screwing around with that quote". (quoted in Toop: 1995, pp. 262-263)

3. See Frith: $2007 \mathrm{~b}$ in which he discusses the evolution of popular music studies as a field and the influence of cultural studies: "musicians and their intentions became less interesting than audiences/consumers and the use of music, the notion of the musical text was broadened to include extra-musical and inter-textual elements, there was less interest in history and tradition than in the immediate, the present, the fashionable, etc. [and] there developed a populist suspicion of claims to 'art' or 'excellence'" (p. 11).

4. Simon Reynolds describes sampladelia as "an umbrella term covering a vast range of contemporary hallucino-genres - trip hop, techno, jungle, house, postrock, swingbeat, and more. 'Sampladelic' refers to disorientating, perceptionwarping music created using the sampler and other forms of digital technology". (Reynolds: 1998, p. 364) See also Demers 2006 for a discussion of sampladelia that interprets the term in relation to a "fascination with sounds deliberately drawn from outside of pop audiences' orbits" (p. 98) such as world music and the avant-garde, which makes her definition slightly problematic in terms of its assumptions about the tastes of popular music listeners. 
5. De La Soul's Posdnuos explains their open-minded approach to appropriation which resonates with Found's attitude to sources of sampling: "We don't exclude anything from playing a part in our music. I think it's crazy how a lot of rappers are just doing the same thing over and over Parliament/Funkadelic/James Brown and all that. I bought Steely Dan's Aja when it first came out, and "Peg" was a song I always loved, so when it came down to making my own music, that was definitely a song I wanted to use. It doesn't make any difference whether a sample is from James Brown, Cheech and Chong, Lee Dorsey, or a TV theme; if there's something that catches my ear, I'll use it". (quoted in Bartlett: 1994, p. 648)

6. Timothy Warner makes this same point after describing how "the first track on Who's Afraid of The Art of Noise?, 'A Time to Fear (Who's Afraid)' begins, after a few introductory sounds, with what appears to be a recording of a political speech in praise of the people of revolutionary Cuba: a recording (in fact a recording within a recording) with explicit cultural references...This speech is far too long to be a digital sample, particularly a Fairlight Series II sample, and has been made using the analogue magnetic tape editing techniques associated with musique concrete. It is interrupted by extremely short drum samples sequenced into a simple $4 / 4$ dance pattern - a typical product of the Fairlight CMI. The stark contrast between these two essentially similar ideas - they are, after all, both derived from prerecorded material - highlights the difference in practice between musique concrete, which is firmly associated with the musical avant-garde, and the kind of sequenced samples found in pop music: the sequencer/sampler arrangement enables and encourages the specifically rhythmic use of pre-recorded music". (Warner: 2003, p. 99)

7. For more on Zhou Xuan and Chinese popular music of the 1930s, see Stock: 1995.

8. The sounds of trains and automobiles were integral to popular music throughout the twentieth century. Peter Shapiro writes that "the rhythm of life in most of America was created by the railroad, and pre-war blues and Country records were often little more than imitations of the locomotive using jugs and guitars". (Shapiro: 2002, p. 134) He looks to New Orleans for the roots of many rhythms and two of its most famous inhabitants would equip themselves with analogue technology to sample the rhythms of truck engines. Aaron Neville remembers how, "Me and [Allen] Toussaint would ride around with a tape recorder and one day we pulled up next to a big semi-truck. The motor was going 'rumble rum rumble' with a nice beat, you know, and Toussaint recorded that beat". (quoted in Rose: 1994, p. 82)

9. Prior (2008, p. 914) writes that the laptop is "an all-in-one production unit that meshes composition with dissemination and consumption. This is what differentiates the laptop from other mobile music devices such as the fourtrack portastudio, Walkman or miniature keyboard. In effect, it is a metainstrument, potentially containing all sounds (a feature it shares with the sampler) and production processes (a feature that transcends the sampler's capabilities)".

10. According to Prior, "in the domain of music, the idea of the "amateur" has been given especially short shrift. Indeed, with the exception of Ruth Finnegan's (1989) now classic ethnography of music-making in a small English town, very few studies have tackled the amateur in any detail. Finnegan herself notes how musicological analysis has gravitated to the "best" or "highest" forms of music-making. In popular music studies this has meant skewed attention to the highly commodified and spectacular domains of the large-scale sub-field". (Prior: forthcoming)

11. In an interview with fellow musician Paul Schutze, Eno explained that "the important thing, as anyone who's played synthesizers knows, is not the number of options that you have, but the rapport you can have with the instrument. This is why people playing crappy 35 year old electric guitars consistently come up with more interesting results, musically, than synthesizer players do. Because what you are thrilled by is not a new sound as such, but a new type of rapport that you feel" (Eno: 1995). 


\section{References}

Auner, Joseph. 2000. "Making Old Machines Speak: Images of Technology in Recent Music", Echo, 2/2.

Barr, Tim. 2008. "Lost and Found", News of the World, 20 April, p. 53.

Bartlett, Andrew. 1994. "Airshafts, Loudspeakers, and the Hip Hop Sample: Contexts and African American Musical Aesthetics", African American Review, Vol. 28, No. 4, pp. 639-652.

Bates, Eliot. 2004. "Glitches, Bugs, and Hisses: The Degeneration of Musical Recordings and the Contemporary Musical Work" in Washburne, C. \& Derno, M. eds. Bad Music: The Music we Love to Hate, Routledge, New York.

Beadle, Jeremy, J. 1993. Will Pop Eat Itself? Pop Music in the Soundbite Era, Faber and Faber, London.

Brovig-Hanssen, Ragnhild. 2010. "Opaque Mediation: The Cut-and-Paste Groove in DJ Food's "Break"” in Danielsen, A. ed. Musical Rhythm in the Age of Digital Reproduction, Ashgate, Aldershot.

Butler, Mark. 2006. Unlocking the Groove: Rhythm, Meter, and Musical Design in Electronic Dance Music, Indiana University Press, Bloomington.

Campbell, Ziggy. 2008. Interview by the author, Minidisc Recording, Edinburgh, 11 October.

Cascone, Kim. 2000. "The Aesthetics of Failure: "Post-Digital" Tendencies in Contemporary Computer Music", Computer Music Journal, 24:4, pp. 12-18.

Clark, Philip. 2009. "Interior Designs”, The Wire, July, pp. 36-39.

Danielsen, Anne. 2006. Presence and Pleasure: The Funk Grooves of James Brown and Parliament, Wesleyan University Press, Middletown.

Demers, Joanna. 2006. Steal This Music: How Intellectual Property Law affects Musical Creativity, University of Georgia Press, Athens.

Drummond, Bill. 2001. 45, Abacus, London.

Drummond, Bill. 2008. 17, Beautiful Books, London.

Eno, Brian. 1995. "Strategies for Making Sense", The Wire, September, pp. 34-38.

Eno, Brian. 2004. "The Studio as Compositional Tool" in Cox, C. \& Warner, D. eds. Audio Culture: Readings in Modern Music, Continuum, London.

Frith, Simon. 1993. "Music and Morality" in Frith, S. ed. Music and Copyright, Edinburgh University Press, Edinburgh.

Frith, Simon. 2001. "The Popular Music Industry" in Frith, S., Straw, W. \& Street, J. eds. The Cambridge Companion to Pop and Rock, Cambridge University Press, Cambridge.

Frith, Simon. 2007a. "Can Music Progress? Reflections on the History of Popular Music", Musicology (Serbia), No. 7. pp. 247-257.

Frith, Simon. 2007b. "Is Jazz Popular Music?”, Jazz Research Journal, 1.1. pp. 8-23.

Frith, Simon. 2010. "Analysing Live Music in the UK: Findings One Year into a ThreeYear Research Project”, IASPM Journal, 1.1. pp.1-3.

Frith, Simon and Horne, Howard. 1987. Art into Pop, Metheun, London.

Frith, Simon and Marshall, Lee. 2004. "Making Sense of Copyright" in Frith, S. \& Marshall, L. eds. Music and Copyright (Second Edition), Edinburgh University Press, Edinburgh.

Gould, Glenn. 1987. "The Prospects of Recording" in Page, T. ed. The Glenn Gould Reader, Faber, London. 
Gray, John. 2004. "Progress, the moth-eaten musical brocade" in Heresies: Against Progress and other Illusions, Granta, London.

Greenfield, Steve and Osborn, Guy. 2004. "Copyright Law and Power in the Music Industry" in Frith, S. \& Marshall, L. eds. Music and Copyright (Second Edition), Edinburgh University Press, Edinburgh.

Harkins, Paul. 2010. "Microsampling: From Akufen's Microhouse to Todd Edwards and the Sound of UK Garage" in Danielsen, A. ed. Musical Rhythm in the Age of Digital Reproduction, Ashgate, Aldershot.

Herbert, Matthew. 2005. "Personal Contract for the Composition of Music", 5 November $2008<$ <ttp://www. matthewherbert.com/pccom.php $>$.

Johnson, Phil. 1996. Straight outa Bristol: Massive Attack, Portishead, Tricky and the Roots of Trip-Hop, Hodder and Stoughton, London.

Kvifte, Tellef. 2007. "Digital Sampling and Analogue Aesthetics" in Melberg, A. ed. Aesthetics at Work, Unipub, Oslo.

Lacasse, Serge. 2000. "Intertextuality and Hypertextuality in Recorded Popular Music" in Talbot, M. ed. The Musical Work: Reality or Invention?, Liverpool University Press, Liverpool.

Martin, George. 1979. All You Need is Ears, St. Martin's Press, New York.

O'Neil, Tim. 2006. "A Thousand Different Keys: A Lunchtime Conversation with

Matthew Herbert", PopMatters, 7 July 2009.

<http://www.popmatters.com/music/interviews/herbert-matthew-060707.shtml>

Page, Will. 2007. "Is Live the Future of Music?", Music Ally, Issue 181.

Perman, Tommy. 2008. Interview by the author, Minidisc Recording, Edinburgh, 11 October.

Prior, Nick. 2008. "OK Computer: Mobility, Software and the Laptop Musician". Information, Communication \& Society", Vol. 11, No. 7. pp.912-932.

Prior, Nick. forthcoming. "The Rise of the New Amateurs: Popular Music, Digital Technology and the Fate of Cultural Production", in Hall, J., Grindstaff, L. \& Lo, M. eds. Culture: A Sociological Handbook, Routledge, London.

Reynolds, Simon. 1998. Energy Flash: A Journey through Rave Music and Dance Culture, Picador, London.

Rodgers, Tara. 2003. "On the Process and Aesthetics of Sampling in Electronic Music Production”, Organised Sound, 8(3). pp. 313-320.

Rogers, Georgie. 2009. "Live Music Overtakes Record Sales", BBC News, 16 March. <http://news.bbc.co.uk/1/hi/entertainment/7945998.stm>

Rose, Tricia. 1994. Black Noise: Rap Music and Black Culture in Contemporary America, Wesleyan University Press, Hanover.

Samagaio, Frank. 2002. The Mellotron Book, ProMusic Press, Vallejo.

Sangild, Torben. 2004. "Glitch - The Beauty of Malfunction" in Washburne, C. \& Derno, M. eds. Bad Music: The Music we Love to Hate, Routledge, New York.

Schloss, Joseph. 2004. Making Beats: The Art of Sample-Based Hip-Hop, Wesleyan University Press, Conneticut.

Schumacher, Thomas, G. 1995. "This is a Sampling Sport': Digital Sampling, Rap Music and the Law in Cultural Production", Media, Culture \& Society, 17. pp. 253-273.

Shapiro, Peter. 2002. "Automating the Beat: The Robotics of Rhythm" in Young, R. ed. Undercurrents: The Hidden Wiring of Modern Music, Continuum, London.

Stock, Jonathan. 1995. "Reconsidering the Past: Zhou Xuan and the Rehabilitation of Early Twentieth-Century Popular Music", Asian Music, Vol. 26, No. 2. pp. 119-135. 
Surface Pressure Records. 2006. "Found", 5 November 2008.

$<$ http://records.surfacepressure.net/artists/>

Tamm, Eric. 1995. Brian Eno: His Music and the Vertical Color of Sound, Da Capo Press, New York.

Theberge, Paul. 1997. Any Sound You Can Imagine: Making Music/Consuming Technology, Wesleyan University Press, Middletown.

Thornton, Sarah. 1995. Club Cultures: Music, Media and Subcultural Capital, Polity Press, Cambridge.

Toop, David. 1995. Ocean of Sound: Aether Talk, Ambient Sound and Imaginary Worlds, Serpent's Tail, London.

Wang, Oliver. 2003. Classic Material: The Hip-Hop Album Guide, ECW Press, Toronto. Warner, Timothy. 2003. Pop Music - Technology and Creativity: Trevor Horn and the Digital Revolution, Ashgate, Aldershot.

Wilder, Eliot. 2005. Entroducing, Continuum, London.

Williamson, John and Cloonan, Martin. 2004. "Rethinking the Music Industry", Popular Music, Vol. 26, No. 2. pp. 305-322.

Young, Rob. 2000. "Roll Tape: Pioneer Spirits in Musique Concrete" in Shapiro, P. ed. Modulations: A History of Electronic Music, Caipirinha Productions, New York.

Young, Rob. 2002. "Worship the Glitch: Digital Music, Electronic Disturbance" in Young, R. ed. Undercurrents: The Hidden Wiring of Modern Music, Continuum, London.

Zak, Albin. 2001. The Poetics of Rock: Cutting Tracks, Making Records, University of California Press, Berkeley.

\section{Discography}

Found. 2006. Found Can Move, Surface Pressure Records, UK. Found. 2007. This Mess we Keep Reshaping, Fence Records, UK. Herbert. 2002. Around the House, Soundslike/K7 Records, Germany. The Matthew Herbert Big Band. 2003. Goodbye Swingtime, Accidental Records, UK. The KLF. 1991. The White Room, KLF Communications, UK.

Pete Rock \& C.L. Smooth. 1992. "They Reminisce Over You (T.R.O.Y.)", Elektra, UK. Tom Scott with the California Dreamers. 1968. Honeysuckle Breeze, Impulse Records, USA. 